\title{
Desverdecimento e armazenamento refrigerado de tangor 'Murcott' em função de concentração e tempo de exposição ao etileno
}

\section{Degreening and cold storage of 'Murcott' tangor as function concentration and exposure time to ethylene}

\author{
Maria Luiza Lye Jomori ${ }^{1}$; Fabiana Fumi Cerqueira Sasaki; \\ Natalia Dallocca Berno ${ }^{3}$; Liliane Cristine Gimenes ${ }^{4}$; Ricardo Alfredo Kluge ${ }^{5 *}$
}

\begin{abstract}
Resumo
O desverdecimento tem sido aplicado em países tradicionalmente exportadores e consumidores de citros frescos como forma melhorar a coloração externa, principalmente em regiões onde as temperaturas não são suficientemente baixas para a carotenogênese durante a maturação dos frutos. No Brasil, esta técnica é realizada de forma empírica, sem controle das condições de aplicação, e os frutos mostram baixa qualidade externa. Este estudo foi realizado com o objetivo de determinar as condições do desverdecimento de tangor 'Murcott', envolvendo a aplicação de etileno exógeno. Etileno nas concentrações de 5 e $10 \mathrm{~mL} \mathrm{~L}^{-1}$ foi aplicado em câmara durante 96 e 120 horas, em temperatura de $25^{\circ} \mathrm{C}$ e umidade relativa de $90 \%$. Depois de tratados, os frutos foram armazenadas a $5^{\circ} \mathrm{C}$ durante 30 dias e, depois disso, mais 3 dias a $25^{\circ} \mathrm{C}$ (comercialização simulada). Os frutos foram avaliados em quatro períodos: depois da colheita, após o tratamento de desverdecimento, após o armazenamento refrigerado e após a comercialização simulada. Os parâmetros analisados foram: coloração da epiderme, teor de sólidos solúveis (SS), acidez titulável (AT), ratio (SS/AT), teor de ácido ascórbico, porcentagem de suco, teor de clorofila total e carotenoides, atividade da enzima clorofilase, taxa respiratória e taxa de produção de etileno. Frutos tratados com etileno, independente da dose, apresentaram aumento do índice de cor, acompanhados pela maior atividade da clorofilase e menor teor de clorofila. Não houve diferença para o teor de carotenoides nos períodos avaliados. Os tratamentos não interferiram o teor de sólidos solúveis, a acidez titulável, ratio, a porcentagem de suco e o conteúdo de ácido ascórbico. Frutos tratados com etileno nas duas concentrações apresentaram maior produção de etileno, sendo que a dose de $10 \mathrm{~mL} \mathrm{~L}^{-1}$ favoreceu a incidência de podridões. A aplicação de etileno $5 \mathrm{~mL} \mathrm{~L}^{-1}$ durante 96 horas já é suficiente para desencadear o processo de desverdecimento de tangor 'Murcott'e pode ser utilizada para melhorar a coloração externa dessa cultivar.
\end{abstract}

Palavras-chave: Citrus reticulata Blanco $x$ Citrus sinensis Osbeck, clorofila, carotenóides, índice de cor

\begin{abstract}
Degreening treatment has been applied in traditional countries exporters and consumers of fresh citrus to improve rind color of fruit cultivated in regions that no shown low temperature during maturation. In Brazil, this technique is performed empirically, without control of application conditions and fruit
\end{abstract}

\footnotetext{
${ }^{1}$ Discente do Curso de Pós-Graduação em Fitotecnia da Escola Superior de Agricultura "Luiz de Queiroz", ESALQ/USP, Piracicaba, SP. E-mail: ml_jomori@yahoo.com.br

${ }^{2}$ Pesquisadora da EMBRAPA Mandioca e Fruticultura, Cruz das Almas, BA. E-mail: fabiana.sasaki@embrapa.br

${ }^{3}$ Discente do Curso de Pós-Graduação em Ciência dos Alimentos, ESALQ/USP, Piracicaba, SP. E-mail: n_dberno@hotmail.com

${ }^{4}$ Discente do Curso de Graduação em Engenharia Agronômica da ESALQ/USP, Piracicaba, SP. E-mail: liliane_gimenes@hotmail. com

${ }^{5}$ Prof. do Dept ${ }^{\circ}$ de Ciências Biológicas, ESALQ/USP, Piracicaba, SP. E-mail: rakluge@usp.br

* Autor para correspondência
} 
shown low extern quality. This study was carried out with the objective to determinate conditions to the technique of postharvest degreening of 'Murcott' orange, involving the application of exogenous ethylene. The concentrations 5 and $10 \mathrm{~mL} \mathrm{~L}^{-1}$ of ethylene was applied inside the chamber for 96 and 120 hours at $25^{\circ} \mathrm{C}$ and $90 \% \mathrm{RH}$. After treatments fruit were stored at $5^{\circ} \mathrm{C}$ during for 30 days, and after that, plus 3 days at $25^{\circ} \mathrm{C}$. Fruit were evaluated in four periods: after harvest; after degreening treatment, after cold storage and after 3 days at $25^{\circ} \mathrm{C}$ (simulated marketing). The variable analyzed were: skin color, soluble solids (SS), titratable acidity (TA), ratio (SS/TA), ascorbic acid, percentage of juice, chlorophyll and carotenoids content, chlorophyllase activity, respiratory rate and ethylene production. The treatments did not affect the soluble solids, titratable acidity, ratio, percentage of juice and ascorbic acid content. Fruit treated with ethylene showed increase of color index concomitant by higher chlorophyllase activity and lower chlorophyll content. There were no differences in the carotenoids content in the periods evaluated. Fruit treated with ethylene at both concentrations had higher ethylene production, whereas the dose of $10 \mathrm{~mL} \mathrm{~L}^{-1}$ favored the incidence of decay. Ethylene $5 \mathrm{~mL} \mathrm{~L}^{-1}$ for 96 hours is enough to trigger the process of degreening 'Murcott' tangor and can be used to improve skin color of this cultivar.

Key words: Citrus reticulata Blanco $x$ Citrus sinensis Osbeck, chlorophyll, carotenoids, color index

\section{Introdução}

O desenvolvimento da cor da epiderme dos citros é grandemente influenciado pela temperatura, sendo que a cor característica da variedade é estimulada por baixas temperaturas durante o período de maturação. Tem sido reportado que as temperaturas ótimas para a transição de cloroplastos para cromoplastos e para a indução de carotenogênese são relativamente baixas (GROSS, 1987). Para a degradação da clorofila é requerida temperaturas noturnas abaixo de $13^{\circ} \mathrm{C}$ (STEARNS; YOUNG, 1942). Além disso, grandes diferenças de temperatura dia/noite (cerca de $20^{\circ} \mathrm{C}$ durante o dia e $7^{\circ} \mathrm{C}$ durante a noite) estimulam a acumulação de xantofilas (YOUNG; ERICKSON, 1961). Assim, para grande parte das regiões brasileira produtoras de citros, caracterizada por dias quentes e/ou com poucas diferenças entre as temperaturas diurnas e noturnas, os citros não desenvolvem a cor típica das variedades, e a epiderme se apresenta com tonalidade amarelo-esverdeada, o que diminui sua aceitação comercial e inviabiliza a exportação.

Em frutos climatéricos, o etileno desempenha importante papel regulador de processos fisiológicos e bioquímicos da maturação, incluindo alterações de cor, amolecimento e acumulação de açúcares, ácidos, vitaminas e compostos aromáticos (BARRY; GIOVANONI, 2007). Em frutos não climatéricos, como os citros, o processo natural de maturação não é acompanhado pelo aumento autocatalítico de etileno e respiração. Entretanto, exposição de citros ao etileno exógeno pode estimular processos associados à maturação, como a degradação da clorofila e a síntese de carotenoides (JACOMINO; MENDONÇA; KLUGE, 2003; MENDONÇA et al., 2003; RODRIGO; ZACARIAS, 2007). Estas alterações de cor são mediadas por enzimas, sendo a clorofila degradada por clorofilase, $\mathrm{Mg}$-dequelatase e outros sistemas enzimáticos e oxidantes (KRÄUTLER, 2008), e os carotenoides sintetizados por meio de múltiplos complexos enzimáticos (KATO et al., 2004). O etileno, ao ser aplicado, aumenta a permeabilidade das membranas celulares favorecendo o acesso do oxigênio, catalisador de reações de oxidação da clorofila (RODRIGO, 2003).

Em países tradicionalmente produtores de citros para consumo in natura e exportação, a técnica do desverdecimento tem sido aplicada como forma de melhorar a qualidade externa do fruto, proporcionando o desenvolvimento da cor típica da variedade, particularmente em tangores, laranjas e tangerinas cultivadas em épocas e/ou regiões não favoráveis de temperatura para a evolução da cor (JIMENEZ-CUESTA; CUQUERELLA; MARTINEZ-JÁVAGA, 1981; KADER; ARPAIA, 1992). 
No Brasil, não há recomendação de condições ideais para o desverdecimento dos citros, sendo que essa técnica é realizada de forma empírica, baseada principalmente nas recomendações realizadas para citros cultivados de outros países, principalmente Espanha e Estrados Unidos. Ainda, no Brasil, quando realizado o tratamento com desverdecimento, não há controle das condições de aplicação no que se refere à concentração e tempo de exposição ao etileno, o que pode originar efeitos indesejáveis, como desenvolvimento de sabores desagradáveis, murchamento e aumento de podridões nos frutos. Em trabalhos realizados por Jacomino, Mendonça e Kluge (2003), e Mendonça et al. (2003), com limão 'Siciliano', e Mayouni et al. (2011), com laranja 'Navel', foi verificado que a aplicação de etileno foi eficiente para o desverdecimento dos frutos, sem afetar parâmetros de qualidade, como teor sólidos solúveis, acidez titulável, teor de ácido ascórbico e porcentagem de suco. Para o tangor 'Murcott' não há informação na literatura de condições para o desverdecimento.

Assim, o objetivo do trabalho foi verificar o efeito do desverdecimento de tangor 'Murcott' com aplicação de etileno em câmara, com condições controladas de concentração e tempos de exposição. Uma vez definida esta tecnologia de desverdecimento, tornar-se-á possível melhorar a qualidade do fruto, proporcionando maior competitividade no mercado externo e aumento do consumo interno brasileiro.

\section{Material e Métodos}

Tangores 'Murcott' foram obtidas na região de Engenheiro Coelho, SP (22 $28^{\circ} 49^{\prime \prime} \mathrm{S}$ e $47^{\circ} 13^{\prime}$ 05 " W), localizadas no clima tropical Cfa (sempre úmido, verão quente). Após a colheita, foram imediatamente transportados para o laboratório, em Piracicaba, SP, e submetidos à rigorosa seleção, obtendo-se um lote uniforme, composto de frutos de tamanho médio, sem defeitos, e apresentando estádio de maturação em que a casca apresenta-se com quebra de coloração verde ("color break"), com índice de cor entre -7 e -2 . Os frutos foram lavados em água corrente com detergente e secados ao ar livre.

A aplicação de etileno foi feita em câmaras herméticas com capacidade de 187 litros. Foi utilizado o produto Etil-5 ${ }^{\circledR}$ (White Martins, Americana, SP), que contém 5\% de etileno e 95\% de nitrogênio. Duas concentrações de etileno foram aplicadas: 5,0 e 10,0 $\mathrm{mL} \mathrm{L}^{-1}$, em dois tempos de exposição: 96 e 120 horas. Essas concentrações e tempos foram definidos com base em pré-testes. A concentração de etileno na câmara foi monitorada por meio de cromatografia. A temperatura durante o desverdecimento foi de $25^{\circ} \mathrm{C}$ e a umidade relativa (UR) foi mantida em $90 \pm 5 \%$. Frutos não tratados com etileno ficaram nas mesmas condições e foram utilizados como controle.

Após os tratamentos, os frutos foram armazenados a $5^{\circ} \mathrm{C}$ e $90 \pm 5 \%$ UR durante 30 dias, sendo submetidos a um armazenamento posterior por 3 dias a $25^{\circ} \mathrm{C}$ e $80 \%$ UR, para simular a comercialização. As análises ocorreram antes da aplicação dos tratamentos, para caracterização inicial (P0), após o desverdecimento (P1), após o armazenamento durante 30 dias a $5^{\circ} \mathrm{C}(\mathrm{P} 2)$ e após a comercialização simulada durante 3 dias a $25^{\circ} \mathrm{C}$ (P3).

As seguintes variáveis foram analisadas:

Cor da epiderme: foi determinado o índice de cor (IC) pela fórmula: $\mathrm{IC}=\left(1000 \mathrm{x} \mathrm{a}^{*}\right) /\left(\mathrm{L}^{*} \mathrm{x}\right.$ $\left.\mathrm{b}^{*}\right)$, de acordo com a metodologia de JimenezCuesta, Cuquerella e Martinez-Jávaga (1981). Os valores de $L^{*}, a^{*}$ e $b^{*}$ foram medidos por meio de um colorímetro Minolta CR-400 (Konica Minolta, Mahwah, New Jersey) com iluminante D-65 e geometria 45/0. O IC varia de -20 a +20 . Quando negativo, o IC indica tonalidades verdes e, quando positivo, tonalidades vermelhas. $\mathrm{O}$ zero corresponde à cor amarela. Foram realizadas 4 leituras na região equatorial de cada fruto, sendo 6 frutos por repetição. 
Teor de sólidos solúveis (SS): determinado em refratômetro digital, com correção automática de temperatura para $20^{\circ} \mathrm{C}$ e os resultados expressos em ${ }^{\circ}$ Brix, conforme metodologia de Ting e Rouseff (1986). Acidez titulável (AT): 10mL do suco recém extraído e filtrado foram diluídos em $90 \mathrm{~mL}$ de água destilada, e titulados potenciometricamente com $\mathrm{NaOH}$ a $0,1 \mathrm{~N}$ até $\mathrm{pH} 8,10$. Os resultados foram expressos em \% de ácido cítrico, segundo metodologia indicada pelo Instituto Nacional de Tecnologia Industrial (1987).

"Ratio": calculado pela relação entre o teor de SS e o de AT.

Teor de ácido ascórbico: $10 \mathrm{~mL}$ de suco recém extraído e filtrado foi diluído em $50 \mathrm{~mL}$ de ácido oxálico, e em seguida titulado com o 2,6-diclorofenol indolfenol-sódico (DCFI), na concentração de $0,002 \%$, até a coloração rosada persistente por 15 segundos. Os resultados foram expressos em $\mathrm{mg}$ de ácido ascórbico por $100 \mathrm{~mL}$ de suco, segundo metodologia de Carvalho et al. (1990).

Porcentagem de suco: cada repetição de 10 frutos foi pesada e teve seu suco extraído em extratora de suco cítrico (Siemsen, Brusque, SC), sendo filtrado e pesado posteriormente, permitindo que a porcentagem de suco fosse calculada através da fórmula: $\%$ de suco $=(\mathrm{MS} / \mathrm{MF})$ x 100 , onde $\mathrm{MS}$ $=$ massa do suco $(\mathrm{g})$ e $\mathrm{MF}=$ massa do fruto $(\mathrm{g})$.

Teor de clorofila total e carotenoides: foram estimados pela metodologia de Lichtenthaler (1987). Para o teor de clorofila, um grama da amostra da epiderme de citros foi triturada e adicionado $10 \mathrm{~mL}$ de acetona $80 \%$ e depois centrifugada por $15 \mathrm{~min}$ a $12000 \mathrm{xg}$ sob $4^{\circ} \mathrm{C}$. Logo após, foi feita a leitura em espectrofotômetro a 645 e $663 \mathrm{~nm}$. O teor de clorofila foi determinado pela equação: $\mathrm{Cl}$ total = 7,15 $\mathrm{A}_{663}+18,71 \mathrm{~A}_{645}$, onde $\mathrm{A}_{645}=$ absorbância a $645 \mathrm{~nm} \mathrm{e}_{663}=$ absorbância a $663 \mathrm{~nm}$. Os resultados foram expressos em $\mathrm{mg}$ de clorofila por $\mathrm{g}$ de casca. Para o teor de carotenoides, um grama da amostra da epiderme de citros foi triturada e adicionado $10 \mathrm{~mL}$ de acetona $80 \%$ e depois centrifugada por
$15 \min$ a $12000 x \mathrm{~g}$ sob $4^{\circ} \mathrm{C}$. Logo após, foi feita a leitura em espectrofotômetro a 470, 645 e 663 nm. O teor de carotenoides foi determinado pela equação: Carot $=\left[1000 \mathrm{~A}_{470}-1,82\left(12,25 \mathrm{~A}_{663}-2,79 \mathrm{~A}_{645}\right)\right.$ - 85,02(21,50 $\left.\left.\mathrm{A}_{645}-5,10 \mathrm{~A}_{663}\right)\right] / 198$, onde $\mathrm{A}_{470}=$ absorbância a $470 \mathrm{~nm}, \mathrm{~A}_{645}=$ absorbância a $645 \mathrm{~nm}$ e $\mathrm{A}_{663}=$ absorbância a $663 \mathrm{~nm}$. Os resultados foram expressos em mg de carotenoides por $\mathrm{g}$ de casca.

Atividade da clorofilase: foi determinada pela metodologia adaptada de Yamauchi, Hashinaga e Itoo (1991). Amostras do flavedo de citros foram congeladas em freezer a $-18^{\circ} \mathrm{C}$ e trituradas em nitrogênio liquido. Após a obtenção do macerado, $1 \mathrm{~g}$ desse material foi filtrado e exaustivamente lavado com acetona $100 \%$, até a remoção completa do pigmento e separando-se o pó cetônico (material sem pigmento). Para o extrato enzimático, $50 \mathrm{mg}$ do pó cetônico da epiderme, com $10 \mathrm{~mL}$ de tampão fosfato de potássio $5 \mathrm{mM}$ ( $\mathrm{pH} 7,0)$, contendo 50 $\mathrm{mM} \mathrm{KCl}$ e $0,24 \%$ Triton X-100 foi mantido por uma hora a $8^{\circ} \mathrm{C}$. A mistura foi centrifugada a velocidade de 12000 xg por $15 \mathrm{~min}$ e o sobrenadante foi utilizado como extrato para a atividade. Para medir a atividade, a reação contendo $0,1 \mathrm{~mL}$ do extrato da enzima, 0,1 mL de 2,64\% Triton X-100, 0,12 $\mathrm{mL}$ de solução de clorofila em acetona e $1,0 \mathrm{~mL}$ de $100 \mathrm{mM}$ de tampão fosfato de potássio $(\mathrm{pH} 7,0)$ foi misturada e incubada em banho-maria a $25^{\circ} \mathrm{C}$ por $20 \mathrm{~min}$. Após esse período, foi adicionado $4 \mathrm{~mL}$ de acetona e $4 \mathrm{~mL}$ de hexano, e realizada a leitura em espectrofotômetro a $663 \mathrm{~nm}$. A atividade foi baseada no decréscimo da absorbância de clorofila: uma unidade de atividade enzimática foi definida pela mudança de 0,01 na absorbância por minuto. O conteúdo de proteínas foi determinado pela metodologia de Bradford (1976), utilizando solução de BSA (Serum Albumine Bovina) para curva padrão.

Para a determinação da taxa respiratória, utilizou-se 4 frutos por frasco de vidro com capacidade de $1000 \mathrm{~mL}$, que permaneceram herméticos por períodos de 1 hora. Em cada tampa dos frascos havia um septo de silicone através do 
qual foi retirada a amostra de gás. Com uma seringa de vidro de $1 \mathrm{~mL}$ injetou-se uma amostra de cada frasco em cromatógrafo a gás (Thermo Electro Corporation, Trace GC Ultra, San Jose, Califórnia, USA) com detector de ionização de chama (FID), tendo hidrogênio como gás de arraste a uma vazão

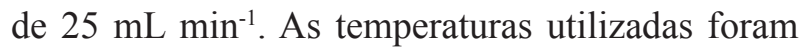
de $80^{\circ} \mathrm{C}$ na coluna, $100^{\circ} \mathrm{C}$ no injetor, $250^{\circ} \mathrm{C}$ no detector e $350^{\circ} \mathrm{C}$ no metanador. Os resultados foram calculados considerando-se as determinações cromatográficas, massa dos frutos, volume livre do frasco e tempo que os frascos permaneceram fechados, sendo expressos em $\mathrm{mL} \mathrm{CO}_{2} \mathrm{~kg}^{-1} \mathrm{~h}^{-1}$.

Para a determinação da taxa de produção de etileno os procedimentos foram semelhantes no que se refere à coleta e injeção da amostra, porém os frascos permaneceram fechados por um período de 2 horas. As temperaturas da coluna, injetor e detector foram de $80^{\circ} \mathrm{C}, 100^{\circ} \mathrm{C}$ e $100^{\circ} \mathrm{C}$, respectivamente. Os resultados foram expressos em $\mu \mathrm{L} \mathrm{C}_{2} \mathrm{H}_{4} \mathrm{~kg}^{-1} \mathrm{~h}^{-1}$.

Os frutos que apresentaram podridões foram encaminhados para a Clínica Fitopatológica Prof. Hiroshi Kimati, no Departamento de Fitopatologia e Nematologia da Esalq/USP, para identificação dos patógenos.

O delineamento experimental adotado foi inteiramente ao acaso, em fatorial $5 \times 4$ (tratamentos $\mathrm{x}$ dias de análise). Foram utilizadas quatro repetições de 10 frutos cada. Os resultados obtidos foram submetidos à análise de variação (teste F), e quando significativa, as médias foram comparadas pelo teste de Tukey a 5\% de probabilidade, pelo programa estatístico SANEST (ZONTA; MACHADO, 1995).

\section{Resultados e Discussão}

Nos frutos tratados com etileno, o IC passou de valores de $-2,26$ (na caracterização) para valores de, aproximadamente, +1,5 logo após o desverdecimento, próximos a $+0,5$ após o armazenamento, e para valores entre $+1,0$ e $+1,5$ após a comercialização simulada (Figura 1A). Observou-se assim acréscimo da intensidade da cor amarela nos frutos tratados com etileno. Nos frutos não tratados, o IC aumentou bem lentamente, atingindo valores de, no máximo, $+0,1$, ao final da comercialização simulada, representando frutos menos amarelados que os tratados com etileno em ambas concentrações. Notou-se ainda nos frutos controle aumento no valor do IC na avaliação efetuada imediatamente após a saída da refrigeração. Esse fato é concordante como foi previamente reportado, que a refrigeração por si só pode incrementar a coloração, deixando citros mais amarelos, como verificado em laranja 'Navelina' armazenada a $12^{\circ} \mathrm{C}$ (CARMONA; ZACARÍAS; RODRIGO, 2012). Entretanto, os valores encontrados para o IC dos frutos tratados com etileno foram sempre maiores, refletindo em melhor cor dos frutos.

Acompanhando o aumento do IC, houve incremento da atividade da clorofilase e concomitante queda no teor de clorofila do flavedo (Figuras 1B e $\mathrm{C}$ ), sendo que os frutos do controle mantiveram os maiores teores de clorofila (Figura 1C). Esses frutos só demonstraram atividade da clorofilase após o armazenamento, com atividade significativamente inferior às dos frutos tratados com etileno (Figura 1B). O etileno exógeno aumenta a expressão gênica da clorofilase, com a formação de produtos da degradação de tonalidade diferente do verde, além de facilitar o acesso do oxigênio para reações de oxidações da clorofila (SHIMOKAWA; SHIMADA; YAEO, 1978; TREBITSH; GOLDSCHMIDT; RIOV, 1993; JOHN-KARUPPIAH; BURNS, 2010). 
Figura 1. Índice de cor (A); atividade de clorofilase (B), Teor de clorofila (C) e teor de carotenoides (D) de tangor 'Murcott' em função de concentração de etileno e tempo de exposição. As análises foram realizadas na caracterização; após o desverdecimento; após o armazenamento refrigerado $\left(30\right.$ dias a $\left.5^{\circ} \mathrm{C}\right)$ e após a comercialização simulada $(3$ dias a $\left.25^{\circ} \mathrm{C}\right)$. Médias seguidas de mesma letra, em cada período de avaliação, não diferem entre si pelo teste de Tukey a $5 \%(n=4)$.
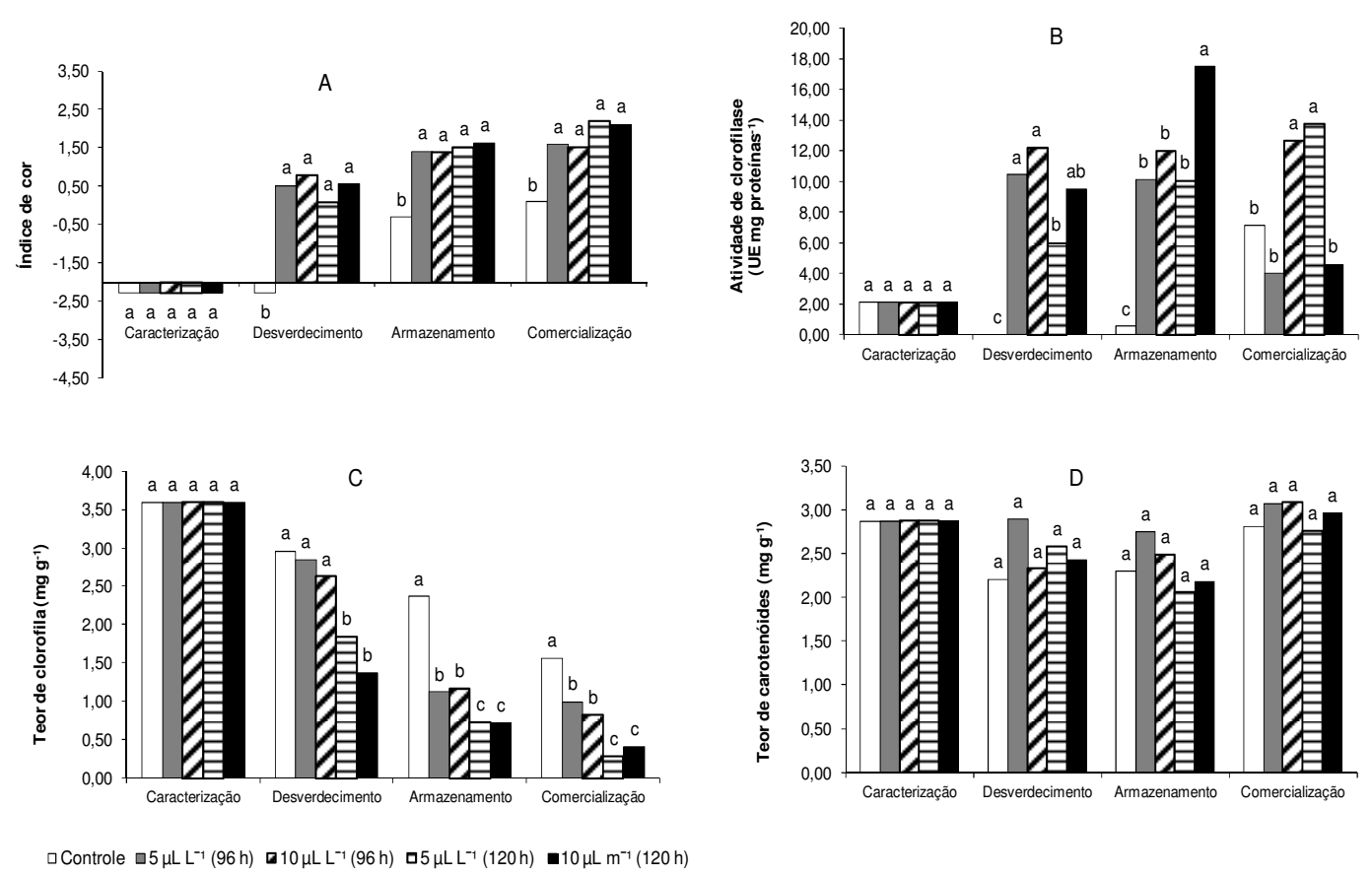

Fonte: Elaboração dos autores.

Para o teor de carotenoides não foram verificadas diferenças significativas nos períodos avaliados e em função dos tratamentos aplicados (Figura 1D). Possivelmente os carotenoides do flavedo já haviam sido sintetizados durante a maturação dos frutos, e o aparecimento da cor amarela (IC) pode ser mais atribuído à degradação da clorofila e não à carotenogênese. A literatura relata que pode haver síntese de carotenoides após a colheita de citros e após a retirada dos frutos da condição refrigerada (CARMONA; ZACARÍAS; RODRIGO, 2012; SALVADOR et al., 2002; ABAD et al., 2003; ZHOU et al., 2010), mas pela extrema susceptibilidade dos compostos à oxidação, pode ter ocorrer um balanço entre síntese e degradação, não permitindo observar variações entre os tratamentos.
Não houve diferenças significativas para os parâmetros de qualidade avaliados (Tabela 1). O teor de SS ficou em torno de $10,6^{\circ}$ Brix, a AT em $0,67 \%$ de ácido cítrico; "ratio" em aproximadamente 16, a \% de suco em $49 \%$ e o teor de ácido ascórbico ao redor de $20 \mathrm{mg} 100 \mathrm{~mL}^{-1}$. Os valores estão concordantes com os descritos para esta cultivar e confirmam resultados de experimentos anteriores onde também não foi observada diferença significativa para estas variáveis em função de tratamentos com etileno para o desverdecimento (MENDONÇA et al., 2003; JACOMINO; MENDONÇA; KLUGE, 2003). Mayuoni et al. (2011), trabalhando com laranjas, pomelos e tangerinas, evidenciaram que os efeitos do etileno exógeno se restringem ao flavedo, não havendo regulação de processos de maturação internos do hormônio. 
Tabela 1. Qualidade interna de tangor 'Murcott' em função de concentração de etileno e tempo de exposição, em análise realizada na caracterização (P0); após o desverdecimento (P1); após o armazenamento durante 30 dias a $5^{\circ} \mathrm{C}$ (P2) e após a comercialização simulada durante 3 dias a $25^{\circ} \mathrm{C}(\mathrm{P} 3)$.

\begin{tabular}{|c|c|c|c|c|c|}
\hline Tratamento & $\mathrm{P} 0$ & P1 & $\mathrm{P} 2$ & P3 & Média \\
\hline & \multicolumn{5}{|c|}{ 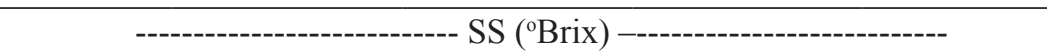 } \\
\hline Controle & 10,23 & 10,78 & 10,50 & 10,33 & $10,46 \mathrm{a}$ \\
\hline $5 \mu \mathrm{L} \mathrm{L}^{-1}(96 \mathrm{~h})$ & 10,23 & 11,58 & 10,93 & 10,60 & $10,84 \mathrm{a}$ \\
\hline $10 \mu \mathrm{L} \mathrm{L}^{-1}(96 \mathrm{~h})$ & 10,23 & 10,75 & 11,05 & 11,10 & $10,78 \mathrm{a}$ \\
\hline $5 \mu \mathrm{L} \mathrm{L}^{-1}(120 \mathrm{~h})$ & 10,23 & 11,23 & 10,80 & 10,60 & $10,72 \mathrm{a}$ \\
\hline $10 \mu \mathrm{L} \mathrm{L}^{-1}(120 \mathrm{~h})$ & 10,23 & 10,70 & 10,73 & 10,65 & $10,58 \mathrm{a}$ \\
\hline \multirow[t]{2}{*}{$\begin{array}{l}\text { Média } \\
\text { C.V. }=3,85 \%\end{array}$} & $10,23 \mathrm{~A}$ & $11,01 \mathrm{~A}$ & $10,80 \mathrm{~A}$ & $10,66 \mathrm{~A}$ & \\
\hline & \multicolumn{5}{|c|}{ 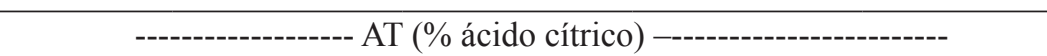 } \\
\hline Controle & 0,65 & 0,65 & 0,75 & 0,60 & $0,66 \mathrm{a}$ \\
\hline $5 \mu \mathrm{L} \mathrm{L}^{-1}(96 \mathrm{~h})$ & 0,65 & 0,78 & 0,69 & 0,64 & $0,69 \mathrm{a}$ \\
\hline $10 \mu \mathrm{L} \mathrm{L}^{-1}(96 \mathrm{~h})$ & 0,65 & 0,70 & 0,71 & 0,72 & $0,70 \mathrm{a}$ \\
\hline $5 \mu \mathrm{L} \mathrm{L}^{-1}(120 \mathrm{~h})$ & 0,65 & 0,69 & 0,73 & 0,58 & $0,66 \mathrm{a}$ \\
\hline $10 \mu \mathrm{L} \mathrm{L}^{-1}(120 \mathrm{~h})$ & 0,65 & 0,73 & 0,74 & 0,60 & $0,68 \mathrm{a}$ \\
\hline \multirow[t]{2}{*}{$\begin{array}{l}\text { Média } \\
\text { C.V. }=8,21 \%\end{array}$} & $0,65 \mathrm{~A}$ & $0,71 \mathrm{~A}$ & $0,72 \mathrm{~A}$ & $0,63 \mathrm{~A}$ & \\
\hline & \multicolumn{5}{|c|}{ 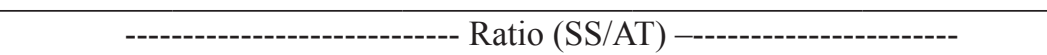 } \\
\hline Controle & 15,78 & 16,61 & 14,21 & 15,64 & $15,56 \mathrm{a}$ \\
\hline $5 \mu \mathrm{L} \mathrm{L}^{-1}(96 \mathrm{~h})$ & 15,78 & 14,94 & 14,51 & 15,31 & $14,92 \mathrm{a}$ \\
\hline $10 \mu \mathrm{L} \mathrm{L}^{-1}(96 \mathrm{~h})$ & 15,78 & 15,41 & 15,75 & 14,87 & $15,34 \mathrm{a}$ \\
\hline $5 \mu \mathrm{L} \mathrm{L}^{-1}(120 \mathrm{~h})$ & 15,78 & 16,48 & 14,58 & 14,77 & $15,28 \mathrm{a}$ \\
\hline $10 \mu \mathrm{L} \mathrm{L}^{-1}(120 \mathrm{~h})$ & 15,78 & 14,69 & 14,20 & 14,75 & $14,55 \mathrm{a}$ \\
\hline \multirow[t]{2}{*}{$\begin{array}{l}\text { Média } \\
\text { C.V. }=6,92 \%\end{array}$} & $15,78 \mathrm{~A}$ & $15,63 \mathrm{~A}$ & $14,65 \mathrm{~A}$ & $15,07 \mathrm{~A}$ & \\
\hline & \multicolumn{5}{|c|}{ 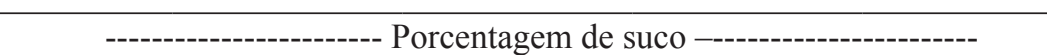 } \\
\hline Controle & 53,65 & 50,16 & 46,62 & 43,04 & $48,37 \mathrm{a}$ \\
\hline $5 \mu \mathrm{L} \mathrm{L}^{-1}(96 \mathrm{~h})$ & 53,65 & 56,25 & 50,62 & 49,14 & $52,42 \mathrm{a}$ \\
\hline $10 \mu \mathrm{L} \mathrm{L}^{-1}$ (96h) & 53,65 & 56,82 & 49,54 & 49,14 & $52,31 \mathrm{a}$ \\
\hline $5 \mu \mathrm{L} \mathrm{L}^{-1}(120 \mathrm{~h})$ & 53,65 & 50,16 & 47,25 & 40,45 & $47,88 \mathrm{a}$ \\
\hline $10 \mu \mathrm{L} \mathrm{L}^{-1}(120 \mathrm{~h})$ & 53,65 & 48,66 & 48,63 & 44,37 & $48,33 \mathrm{a}$ \\
\hline \multirow[t]{2}{*}{$\begin{array}{l}\text { Média } \\
\text { C.V. }=4,49 \% \\
\end{array}$} & $53,65 \mathrm{~A}$ & $52,41 \mathrm{~A}$ & $48,53 \mathrm{~A}$ & $45,25 \mathrm{~A}$ & \\
\hline & \multicolumn{5}{|c|}{----------- Ácido ascórbico $\left(\mathrm{mg} 100\right.$ mL $\mathrm{mL}^{-1}$ ) ----------- } \\
\hline Controle & 19,58 & 21,68 & 18,92 & 20,24 & $20,11 \mathrm{a}$ \\
\hline $5 \mu \mathrm{L} \mathrm{L}^{-1}(96 \mathrm{~h})$ & 19,58 & 19,45 & 20,75 & 17,75 & $19,38 \mathrm{a}$ \\
\hline $10 \mu \mathrm{L} \mathrm{L}^{-1}(96 \mathrm{~h})$ & 19,58 & 19,50 & 20,90 & 20,20 & $20,05 \mathrm{a}$ \\
\hline $5 \mu \mathrm{L} \mathrm{L}^{-1}(120 \mathrm{~h})$ & 19,58 & 21,99 & 19,26 & 19,83 & $20,17 \mathrm{a}$ \\
\hline $10 \mu \mathrm{L} \mathrm{L}^{-1}(120 \mathrm{~h})$ & 19,58 & 22,58 & 19,44 & 20,55 & $20,54 a$ \\
\hline $\begin{array}{l}\text { Média } \\
\text { C.V. }=5,86 \%\end{array}$ & $19,58 \mathrm{~A}$ & $21,04 \mathrm{~A}$ & $19,85 \mathrm{~A}$ & $19,71 \mathrm{~A}$ & \\
\hline
\end{tabular}

Médias seguidas de mesma letra maiúscula na linha e minúscula na coluna não diferem entre si pelo teste de Tukey a 5\% (n=4). Fonte: Elaboração dos autores. 
No presente experimento foi observado que os frutos tratados com $10 \mathrm{~mL} \mathrm{~L}^{-1}$ de etileno durante 120 horas apresentaram $15 \%$ de podridões por Penicillium digitatum, na avaliação realizada após a retirada da câmara fria. Exposições demasiadas ao etileno ou concentrações excessivamente altas, em frutos cítricas podem, de fato, aumentar a incidência de podridões, pois enfraquecem a parede celular das células do flavedo, favorecendo o acesso de patógenos (SMILANICK; MANSOUR; SORENSON, 2006). Nos demais tratamentos não ocorreram podridões.

A taxa respiratória dos frutos aumentou após o tratamento de desverdecimento com duração de 96h, havendo queda na respiração nas avaliações subsequentes (Figura 2A). Comportamento semelhante foi observado para a produção de etileno (Figura 2B). Considerando que o tempo de tratamento de desverdecimento foi relativamente longo (4 - 5 dias) é possível que os picos respiratórios e de produção de etileno tenham sido bem maiores nos primeiros dias após os tratamentos de desverdecimento (1 a 3 dias), o que explica, em parte, o fato dos frutos tratados durante $120 \mathrm{~h}(5$ dias) mostrarem taxas respiratórias menores que aqueles tratados durante $96 \mathrm{~h}$. Assim, provavelmente as avaliações após 96 e 120 h estejam em queda e que valores bem maiores provavelmente foram expressos nos primeiros dias logo após o tratamento. De fato, a reposta de frutos não climatéricos ao etileno exógeno é relativamente rápida, ao contrário dos climatéricos, onde a aplicação exógena de etileno aumenta a sua autocatálise, acompanhada de aumento da respiração para suprir ATP à sua biossíntese. Os picos de etileno e respiração são importantes para a obtenção de respostas positivas dos tratamentos de desverdecimento, considerando que o etileno atua na expressão gênica de enzimas que degradam a clorofila e que estimulam a síntese de carotenoides (TREBITSH; GOLDSCHMIDT; RIOV, 1993; RODRIGO; ZACARIAS, 2007). No presente trabalho ficou demonstrado que a degradação da clorofila parece ter influenciado mais o desenvolvimento da coloração do flavedo do que a síntese de carotenoides (Figura 1C e D).

Assim, ficou constatado que a aplicação do etileno em câmara, com condições controladas de concentração, temperatura e tempo de exposição pode se tornar vantajoso para o tangor 'Murcott', favorecendo a obtenção de cor adequada, sem afetar outros parâmetros de qualidade (SS, AT, ratio, porcentagem de suco e conteúdo de acido ascórbico). Considerando as duas concentrações utilizadas verifica-se que $5 \mathrm{~mL} \mathrm{~L}^{-1}$ durante 96 horas é suficiente para desencadear o processo de desverdecimento desta cultivar, pois praticamente não diferiu da maior concentração e do maior tempo de exposição, que por sua vez favoreceu a incidência de podridões. 
Figura 2. Taxa respiratória (A) e produção de etileno (B) de tangor 'Murcott' em função de concentração de etileno e tempo de exposição. As análises foram realizadas na caracterização; após o desverdecimento; após o armazenamento refrigerado $\left(30\right.$ dias a $\left.5^{\circ} \mathrm{C}\right)$ e após a comercialização simulada $\left(3\right.$ dias a $\left.25^{\circ} \mathrm{C}\right)$. Médias seguidas de mesma letra, em cada período de avaliação, não diferem entre si pelo teste de Tukey a 5\% (n=4).

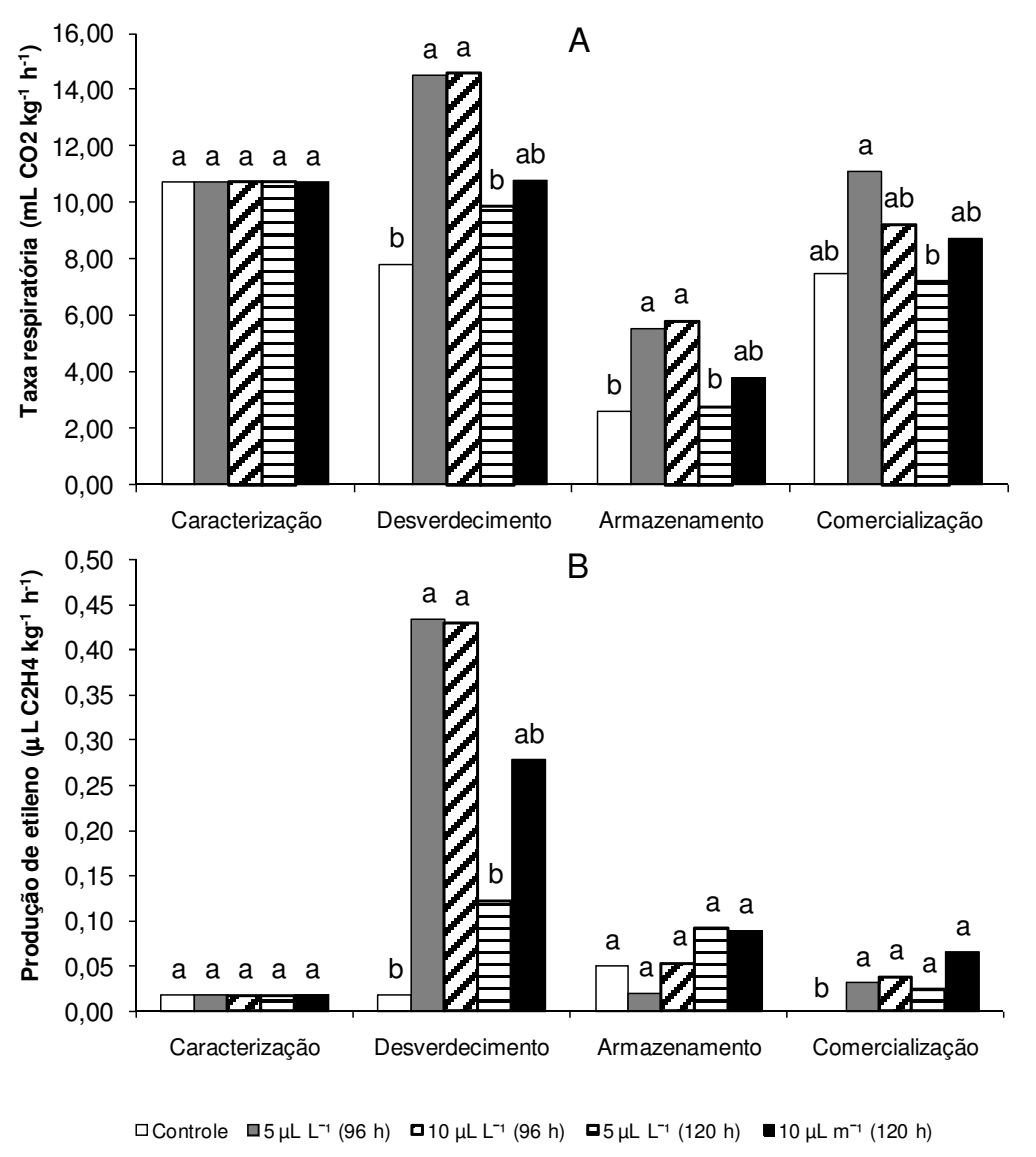

Fonte: Elaboração dos autores.

\section{Agradecimentos}

Os autores agradecem à Fundação de Amparo à Pesquisa do Estado de São Paulo (FAPESP), pelo auxílio à pesquisa (proc. 2006/06536-6), bolsa de doutorado à primeira autora (proc. 2006/05154-2) e bolsa de iniciação científica a quarta autora (proc. 2009/09695-6).

\section{Referências}

ABAD, I.; MARTÍNEZ-JÁVEGA, J. M.; SALVADOR, A.; NAVARRO, P. Aplicación del frío a nuevas variedades de mandarinas y naranjas. Levante Agrícola, Valencia, v. 366, n. 1, p. 236-240, 2003.
BARRY, C. S.; GIOVANONI, J. Ethylene and fruit ripening. Journal of Plant Growth Regulation, Dresden, v. 26, n. 2, p. 143-159, 2007.

BRADFORD, M. A rapid and sensitive method for the quantization of microgram quantifies of protein utilizing the principle of protein-dye binding. Analytical Biochemistry, Bethesda, v. 71, n. 1, p. 248-254, 1976.

CARMONA, L.; ZACARÍAS, L.; RODRIGO, M. J. Stimulation of coloration and carotenoid biosynthesis during postharvest storage of 'Navelina' orange fruit at $12{ }^{\circ}$ C. Postharvest Biology and Technology, Amsterdan, v. 74, n. 12, p. 108-117, 2012.

CARVALHO, C. R. L.; MANTOVANI, D. M. B.; CARVALHO, P. R. N.; MORAES, R. M. M. Análises químicas de alimentos. Campinas: ITAL, 1990. $121 \mathrm{p}$. (Manual técnico). 
GROSS, J. Pigments in fruit. London: Academic Press, $1987.303 \mathrm{p}$.

INSTITUTO NACIONAL DE TECNOLOGIA INDUSTRIAL. Identidad y calidad de los alimentos frutihorticolas. Mendonza: INTI, 1987. 209 p.

JACOMINO, A. P.; MENDONÇA, K.; KLUGE, R. A. Armazenamento refrigerado de limões 'Siciliano' tratados com etileno. Revista Brasileira de Fruticultura, Jaboticabal, v. 25, n. 1, p. 45-48, 2003.

JIMENEZ-CUESTA， M.; CUQUERELLA， J.; MARTINEZ-JÁVEGA, J. M. Determination of a color index for Citrus fruit degreening. Proceedings of the International Society of Citriculture, Riverside, v. 2, p. 750-753, 1981.

JOHN-KARUPPIAH, K. J.; BURNS, J. K. Degreening behavior in 'Fallglo' and 'Lee $\times$ Orlando' is correlated with differential expression of ethylene signaling and biosynthesis genes. Postharvest Biology and Technology, Amsterdan, v. 58, n. 3, p. 185-193, 2010.

KADER, A. A.; ARPAIA, M. L. Postharvest handling system: subtropical fruits. In: KADER, A. A. (Ed.). Postharvest technology of horticultural crops. 2. ed. Oakland: University of California, 1992. p. 233-240.

KATO, M.; IKOMA, Y.; MATSUMOTO, H.; SUGIURA, M.; HYODO, H.; YANO, M. Accumulation of Carotenoids and expression of carotenoid biosynthetic genes during maturation in citrus fruit. Plant Physiology, Glasgow, v. 134, n. 2, p. 824-837, 2004.

KRÄUTLER, B. Chlorophyll breakdown and chlorophyll catabolites in leaves and fruit. Photochemical and Photobiological Sciences, Cambridge, v. 7, n. 10, p. 1114-1120, 2008.

LICHTENTHALER, H. K. Chlorophylls and carotenoids: pigments of photosynthetic biomembranes. Methods Enzymology, Pasadena, v. 148, n. 2 p. 350-382, 1987.

MAYUONI, L.; TIETEL, Z.; PATIL, B. S.; PORAT, R. Does ethylene degreening affect internal quality of citrus fruit? Postharvest Biology and Technology, Amsterdan, v. 62 , n. 1, p. 50-58, 2011.

MENDONÇA, K.; JACOMINO, A. P.; MELHEM, T. X.; KLUGE, R. A. Concentração de etileno e tempo de exposição para desverdecimento de limão 'Siciliano'. Brazilian Journal of Food Technology, Campinas, v. 6, n. 2, p. 179-183, 2003.

RODRIGO, M. J. Desverdizado del frutos citricos. Terralia, Madrid, n. 36, p. 60-66, 2003.
RODRIGO, M. J.; ZACARIAS, L. Effect of postharvest ethylene treatment on carotenoid accumulation and the expression of carotenoid biosynthetic genes in the flavedo of orange (Citrus sinensis L. Osbeck) fruit. Postharvest Biology and Technology, Amsterdan, v. 43, n. 1, p. 14-22, 2007.

SALVADOR, A.; MONTEVERDE, A.; VÁZQUEZ, D.; CUQUERELLA, J.; NAVARRO, P. Desverdización de frutos cítricos con destino a paises de ultramar. Levante Agrícola, Valencia, n. 361, p. 238-244, 2002.

SHIMOKAWA, K.; SHIMADA, S.; YAEO, K. Ethyleneenhanced chlorophyllase activity during degreening of Citrus unshiu MARC. Scientia Horticulturae, Amsterdan, v. 8, n. 2, p. 129-135, 1978.

SMILANICK, J. L.; MANSOUR, M. F.; SORENSON, D. Pre-and postharvest treatments to control green mold of citrus fruit during ethylene degreening. Plant Disease, Davies, v. 90, n. 1, p. 89-96, 2006.

STEARNS, C. R.; YOUNG, G. T. The relation of climatic conditions to color development in citrus fruit. Proceedings of the Florida State Horticultural Society, Orlando, v. 55, p. 59-61, 1942.

TING, S. V.; ROUSEFF, R. L. Citrus fruits and their products: analysis y technology. New York: Marcel Dekker, 1986. 293 p.

TREBITSH， T.; GOLDSCHMIDT, E.; RIOV， J. Ethylene induces de novo synthesis of chlorophyllase, a chlorophyll degrading enzyme, in Citrus fruit peel. Plant Biology, Stuttgart, v. 90, n. 20, p. 9441-9445, 1993.

YAMAUCHI, N.; HASHINAGA, S.; ITOO, S. Chlorophyll degradation with degreening of Kabosu (Citrus sphaerocarpa Hort ex Tanaka) fruits. Journal of the Japanese Society for Horticultural Science, Tsushima v. 59, n. 4, p. 869-875, 1991.

YOUNG, L. B.; ERICKSON, L. C. Influences of temperature on color change in 'Valencia' oranges. Proceedings of the Florida State Horticultural Society, Orlando, v. 78, p. 197-200, 1961.

ZHOU, J. Y.; SUN, C. D.; ZHANG, L. L., DAI, X.; XU, C. J.; CHEN, K. S. Preferential accumulation of orangecolored carotenoids in Ponkan (Citrus reticulata) fruit peel following postharvest application of ethylene or ethephon. Scientia Horticulturae, Amsterdan, v. 126, n. 2, p. 229-235, 2010.

ZONTA, E. P.; MACHADO, A. A. SANEST - sistema de análise estatística para microcomputadores. Pelotas: Registro SEI n. 066060, Categoria A, 1995. 48 p. 